\title{
Feather-degrading bacteria, uropygial gland size and feather quality in House Sparrows Passer domesticus
}

\author{
1 \\ ${ }^{1}$ MTA-DE 'Lendületc' Behavioural Ecology Research Group, Department of Evolutionary Zoology and Human Biology, \\ University of Debrecen, Egyetem tér 1, H-4032, Debrecen, Hungary \\ ${ }^{2}$ Evolutionary Ecology Group, Hungarian Department of Biology and Ecology, Babeș-Bolyai University, Clinicilor Street \\ 5-7, RO-400006, Cluj Napoca, Romania \\ ${ }^{3}$ Department of Wildlife Diseases, Leibniz Institute for Zoo and Wildlife Research, Alfred-Kowalke-Straße 17, \\ 2 \\ DE-10315, Berlin, Germany
}

\begin{abstract}
Feathers are dead integumentary structures that are prone to damage and thus show gradual degradation over the course of a year. This loss of quality might have negative fitness consequences. Feather-degrading bacteria are some of the most prevalent featherdegrading organisms, yet the relationship between feather-degrading bacteria load and flight feather quality has rarely been assessed. We studied this relationship in free-living House Sparrows during breeding and non-breeding annual lifecycle stages. We also considered the size of the uropygial gland, given the antimicrobial function of its secretions, and the effect of body condition. The number of feather holes was positively associated with feather-degrading bacteria load and was negatively related to uropygial gland size and body condition during the breeding season in both sexes. In the non-breeding season we found the same relationships, but only in females. The degree of feather wear was unrelated to any of the variables measured during the breeding season, whereas it was negatively associated with uropygial gland size and positively with feather-degrading bacteria load in the non-breeding season, but only in females. Our results suggest that feather-degrading bacteria may induce the formation of feather holes, but play only a minor role in the abrasion of flight feathers.
\end{abstract}

Keywords: feather hole, feather wear, feather structure, keratinolytic microorganisms, preen oil.

Feathers are epidermal appendages that characterize theropod dinosaurs, including birds. Because they are dead structures, they are incapable of regeneration and therefore their structure abrades gradually with persistent use, particularly in the case of flight feathers (the remiges and rectrices; Vágási et al. 2011, Flinks \& Salewski 2012). Feather abrasion and feather holes are the most commonly encountered signs of structural damage. Of these, feather abrasion (or wear) is the gradual shortening of the flight feather tips (Merilä \& Hemborg 2000, Vágási et al. 2011), whereas feather holes are small defects (diameter 0.5$1 \mathrm{~mm}$ ) of the vane (Vas et al. 2008, Vágási 2014).

${ }^{*}$ Corresponding authors.

Emails: fafeldolgozo@gmail.com; csvagasi@gmail.com
Feather structural damage could decrease flight feather quality and/or create asymmetry in the wing and tail. Consequently, such damage might impose fitness costs via reduced flight performance (e.g. manoeuvrability, take-off speed or wing-beat frequency; Swaddle et al. 1996, 1999, Swaddle \& Witter 1998, Barbosa et al. 2003).

Feather structure can be impaired by both abiotic and biotic environmental factors. Feather abrasion is recognized as a direct consequence of mechanical friction (Burtt 1986, Francis \& Wood 1989, Jenni \& Winkler 1994). In addition, Moreno-Rueda (2011) proposed that the degree of abrasion might also be exacerbated by ectoparasites (e.g. chewing lice, feather-degrading bacteria). Feather holes are usually considered to be the feeding traces of chewing lice (Møller 1991) but a 
recent review suggests this conclusion to be contentious, as damage could be caused by other parasites (e.g. feather-degrading bacteria) and/or mechanical agents (Vágási 2014, see also Vágási et al. 2011). These assumptions, however, have never been explored.

Feather-degrading bacteria (FDB) are a widespread group of microorganisms that live on the plumage of birds (Burtt \& Ichida 1999, Gunderson 2008). They possess keratinolytic enzymes that hydrolyse the keratin matrix (Ramnani et al. 2005), leading to complete degradation of feathers in vitro (Ichida et al. 2001, Ramnani et al. 2005, Ruiz-Rodríguez et al. 2009). However, this interaction might be more intricate than depicted by in vitro studies, as some peculiarities of FDB break down in vivo (Czirják et al. 2013), and the in vivo association between FDB and plumage condition is still largely unexplored (Gunderson 2008, exceptions are Jacob et al. 2014a, Leclaire et al. 2015).

Birds are equipped with multiple defence mechanisms that have evolved to protect them against biotic impacts on their feathers, such as feather structure and coloration, body maintenance behaviours and moult (reviewed by Gunderson 2008, but see also Bonser 1995, Burtt \& Ichida 1999, Saranathan \& Burtt 2007, Giraudeau et al. 2010a, Burtt et al. 2011). One prominent adaptation is the oily secretion of the uropygial gland (UG) (Jacob \& Ziswiler 1982). The UG is an epidermal holocrine gland of birds that produces preen oil, which is spread onto the plumage during preening. Various functions are attributed to the preen oil, such as improving the resistance of flight feathers to mechanical friction (Moreno-Rueda 2011) and acting as an antimicrobial barrier to keratinolytic microorganisms (Jacob et al. 1997, Shawkey et al. 2003, Soler et al. 2008, Møller et al. 2009, Martín-Vivaldi et al. 2010). It has also been shown that UG size is inversely related to the number of feather holes (Moreno-Rueda 2010, 2014), suggesting that the volume of preen oils available might influence the formation of holes. Although most studies attribute an important role to preen oil in improving feather quality, the relationship of feather damage, FDB and UG size has remained little studied.

We studied free-ranging House Sparrows Passer domesticus to assess the relationships between FDB load and flight feather quality by also taking into account the potential mediating effects of UG size and body condition. Birds were sampled in two dif- ferent stages of their annual cycle, breeding and non-breeding, which differ markedly in terms of feather damage (Vágási et al. 2011), FDB prevalence (Burtt \& Ichida 1999) and UG volume (Pap et al. 2010). We assessed whether: (1) feather quality is related to FDB abundance, UG size and body condition, (2) UG size and body condition are associated with FDB load and (3) these relationships differ between seasons and sexes. Based on the expectation that keratinolytic parasites could induce the formation of feather holes by disrupting a feather's structural integrity (Vágási 2014), we predicted a positive relationship between feather damage (i.e. degree of feather wear and feather hole load) and FDB abundance. We expected a negative relationship between the feather damage and UG size, in line with former studies (MorenoRueda 2010, 2011, 2014). Finally, we predicted a 3 positive relationship between FDB abundance and UG size, as some recent studies indicated that UG size increases with experimentally elevated microbial pressure (Jacob et al. 2014b, Leclaire et al. 2015, but see Møller et al. 2009).

\section{METHODS}

\section{General procedures}

We caught respectively 48 (26 males and 22 females) and 74 (39 males and 35 females) House Sparrows with mist-nets (Ecotone, Poland) during 5 the breeding (May 2012) and non-breeding seasons (November 2012) at a farm near Bălcaciu Village, central Transylvania, Romania $\left(46^{\circ} 11^{\prime} 28^{\prime \prime}\right.$ $\mathrm{N}, 2^{\circ} 3^{\prime} 41^{\prime \prime} \mathrm{E}$ ). All birds captured in May were adults (i.e. at least 1 year old); however, individuals caught in November were either adults or firstyear individuals. While males can be aged based on the 'mask of seniority' (Nakagawa \& Burke 2008), first-year and adult females cannot be distinguished based on plumage characters after the complete post-juvenile moult. To overcome pseudoreplication, we did not sample the individuals recaptured in November.

Birds were ringed and standard biometric data were recorded: tarsus length $( \pm 0.01 \mathrm{~mm}$ with digital callipers), body mass ( $\pm 0.1 \mathrm{~g}$ with a Pesola spring balance) and UG size. The volume of the UG $\left(\mathrm{mm}^{3}\right)$ is the product of maximum width, length and height $( \pm 0.01 \mathrm{~mm}$ with digital callipers; see Pap et al. 2010). To increase the precision of our data, UG size was measured twice and 
then averaged for each individual. Measurement precision was very high as shown by the large repeatability of UG volume both during the breeding $\quad(r=0.964, \quad 95 \% \quad$ confidence interval $(\mathrm{CI})=0.943-0.984, P<0.001)$ and non-breeding seasons $\quad(r=0.961, \quad 95 \% \quad C I=0.944-0.979$, $P<0.001)$. Gland volume correlates with the amount of secretion produced in House Sparrows (Pap et al. 2010), therefore volume is a good proxy of the secretory capacity of the UG (Møller et al. 2009).

\section{Feather quality}

Flight feather quality was characterized by two measures of feather damage: the degree of feather wear and the number of feather holes. Feather wear was scored separately for each of the 18 remiges of the left wing (the outermost primary is vestigial in sparrows) following Prater et al. (1977) as follows: $0=$ unworn (i.e. immaculate feather tip), 1 = slightly, $2=$ moderately, and 3 =very abraded (i.e. a considerably shorter feather, even with breakage at the tip). The scores of individual feathers were summed for an overall wing wear index. Feather holes were counted separately on the remiges of the left wing and on tail feathers, then individual counts were summed to obtain a total hole load (see also Vágási et al. 2011). Both parameters were quantified by the same person (CIV).

\section{Abundance of feather-degrading bacteria}

Immediately after capture, we collected approximately five belly feathers following the method described by Czirják et al. (2013). We collected feather samples only from the belly, as it has been shown previously that bacterial abundances from different body regions of the same individual are positively correlated (Pearson's product-moment correlation of belly feathers vs. primary and secondary remiges: $t=3.424, \mathrm{df}=128, P<0.001$, $r=0.289,95 \%$ CI of $r=0.123-0.439$, A. Fülöp, G. Á. Czirják, P. L. Pap \& C. I. Vágási unpubl. data from the same population; see also Gunderson et al. 2009). We took every measure to exclude the exogenous contamination of feathers. Briefly, before handling the birds, we washed our hands with ethanol (70\%) and waited for this to evaporate completely to avoid the unintentional killing of any bacteria on the feathers. Then we collected the feather samples using forceps that had been sterilized with ethanol (70\%) and heat (flamed for at least $10 \mathrm{~s}$ ). Feather samples were stored in sterile cryotubes and kept at $4{ }^{\circ} \mathrm{C}$ in a dark cool box until arriving at the laboratory (within $10 \mathrm{~h}$ ), where samples were stored at $-20^{\circ} \mathrm{C}$ until microbiological analyses took place. Further details are described elsewhere (Czirják et al. 2013).

The abundance of FDB (interchangeably used with FDB load) was measured under sterile conditions in the laboratory using the microbiological techniques described by Czirják et al. (2010). A detailed description of the methodology can be found in Appendix S1. FDB load was expressed as the number of colony-forming units per $\mathrm{mg}$ of feather (CFU/mg feather). These values were also used in the subsequent statistical analyses. All laboratory procedures and counts were performed blind with respect to the identity of individual birds and conducted by the same person (A.F.).

\section{Statistical analyses}

Statistical analyses were carried out using the R statistical environment, version 3.1.1 (R Core Team 2014). Body condition was expressed as scaled mass index (SMI; Peig \& Green 2009), which is a size-corrected body condition index calculated by the function $\mathrm{SMI}=$ body mass $\times(19.14 /$ tarsus length) ${ }^{1.65}$, where 19.14 is the mean tarsus length of the sample, and 1.65 is the slope of a model II standard major axis regression of log mass on log tarsus length calculated from the sampled individuals (R package 'lmodel2'; Legendre 2014). Prior to analyses, FDB load was $\log _{10}$-transformed to improve its distribution, and SMI, UG size and FDB load were scaled such that the mean $=0$ and $s d=1$ using the 'scale' function in $\mathrm{R}$, which subtracts the sample mean from each individual's value and divides this by the sample sd.

To assess seasonal and sex differences in the measured traits we used generalized linear models (GLMs) with quasi-Poisson error distribution for the feather quality markers (feather holes and wear) and linear models (LM) with Gaussian distribution for SMI, UG size and FDB load. Traits were entered in separate models as dependent variables, with season, sex and their interaction as independent terms. Relationships between feather quality traits (feather holes and wear), entered as 
dependent variables in the models, and sex, FDB load, UG size and SMI were assessed using GLMs with quasi-Poisson error distribution separately for the two seasons (breeding/non-breeding). The interactions between sex and other continuous predictors were also tested in all models. FDB load was analysed separately for the two seasons using LMs with Gaussian distributions. FDB load was entered as a dependent variable, whereas sex, UG size, SMI and the interaction of sex with UG size and SMI were included as independent terms.

In all cases, we first built saturated models that were simplified to minimum adequate models (MAMs) using a backward stepwise elimination procedure dropping non-significant $(P>0.05)$ predictors and/or interactions with the largest $P$-value during each step. Exceptions were those non-significant main effects that were part of a significant interaction. Requirements of MAMs related to linearity, outliers and residual distribution were checked by plot diagnosis, and the potential multicollinearity issue between predictors was assessed by computing the variance inflation factor (VIF; R package 'car'; Fox \& Weisberg 2011). Because all VIF $<4.61$, we concluded that there was no multicollinearity that might alter our conclusions. Only the MAMs are presented in the main text (results of the full models are given in Tables S1S4).

The reference levels for the factors season and sex are breeding season and males, respectively. Thus, negative values for season indicate that the averages are smaller during the non-breeding season, and negative values associated with sex indicate that sex-specific averages tend towards females. Model estimates $(\beta) \pm$ se are reported throughout, and results are considered significant if $P \leq 0.05$.

\section{RESULTS}

Each House Sparrow was infested with FDB (i.e. prevalence was $100 \%$ in both seasons) and the median, mean and sd for FDB load were 16.33, 25.71 and 22.93 during breeding (range: 4.40123.75 ) and $17.81,43.90$ and 66.46, during nonbreeding (range: 2.41-383.42), respectively.

\section{Seasonal and sex differences}

The extent of feather wear and the number of feather holes was significantly greater during the breeding season compared with the non-breeding season (wear: $\beta=-2.765 \pm 0.171, t=16.130$, $P<0.001$; holes: $\beta=-1.050 \pm 0.184, t=5.691$, $P<0.001)$. The number of feather holes was significantly greater in males than in females $(\beta=-0.478 \pm 0.184, \quad t=2.590, \quad P=0.010)$, whereas feather wear was similar between the sexes.

Body condition (i.e. SMI) was similar between seasons and sexes. The size of the UG differed between seasons sex-dependently (UG $\times$ sex interaction: $\beta=-0.780 \pm 0.254, t=3.069, P=$ $0.002)$; sexes were similar in UG volume during the non-breeding season $(\beta=-0.012 \pm 0.129$, $t=0.097, P=0.923$ ), but females had larger UG than males during the breeding period $(\beta=0.767 \pm 0.244, t=3.137, P=0.002)$. Variation in FDB loads was not explained by either season or sex.

\section{Feather quality during breeding}

The number of feather holes was negatively related to body condition (i.e. SMI) and UG size, and was positively associated with FDB load (Fig. 1a,c, Table 1). The extent of feather wear was not explained by any of the predictors (Table 1).

\section{Feather quality during non-breeding}

The number of feather holes differed significantly between the sexes, males having more holes than females. The number of feather holes was also related to UG size and FDB load in a sex-dependent way, as shown by the significant twoway interactions (Table 1). In males, the number of feather holes was unrelated to SMI $(\beta=-0.168 \pm 0.194, t=0.866, P=0.392), \mathrm{UG}$ $(\beta=-0.077 \pm 0.185, \quad t=0.418, \quad P=0.678)$ or FDB $(\beta=-0.080 \pm 0.200, t=0.398, P=0.693$; Fig. $1 \mathrm{~b}$ ), whereas in females it was significantly negatively related to SMI $(\beta=-0.399 \pm 0.185$, $t=2.153, \quad P=0.039) \quad$ and $\quad$ UG size $(\beta=-0.633 \pm 0.196, t=3.226, P=0.002)$, and positively to FDB load $(\beta=0.485 \pm 0.188$, $t=2.430, P=0.021$; Fig. $1 \mathrm{~d}$ ).

The degree of feather wear was significantly negatively related to UG size, and was sex-dependently related to FDB load, as indicated by the significant sex $\times$ FDB interaction (Table 1). The degree of feather wear was not related to SMI 


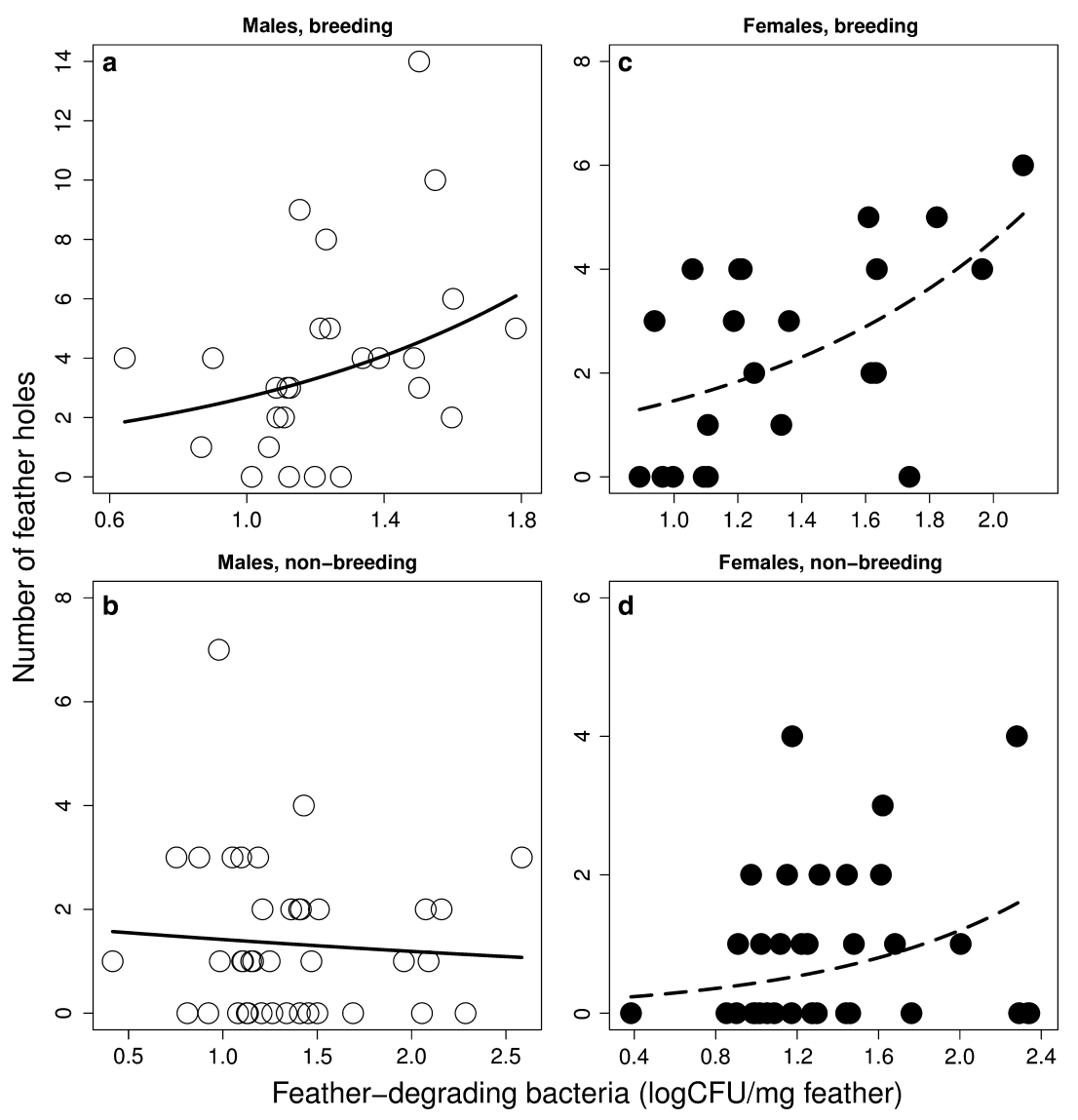

Figure 1. Relationships between the abundance of feather-degrading bacteria and the number of feather holes in House Sparrows Passer domesticus for the different sexes and seasons ((a) breeding males; (b) non-breeding males; (c) breeding females; (d) nonbreeding females).

$(\beta=-0.042 \pm 0.272, t=0.155, P=0.877), \mathrm{UG}$ size $(\beta=-0.235 \pm 0.263, t=0.892, P=0.378)$ or FDB load $(\beta=-0.140 \pm 0.287, t=0.490$, $P=0.627)$ in males, but it was significantly negatively related to UG size $(\beta=-0.827 \pm 0.275$, $t=2.999, P=0.005)$, and positively to FDB abundance $(\beta=0.884 \pm 0.271, t=3.261, P=0.002)$ in females.

\section{Feather-degrading bacteria load}

Feather-degrading bacteria load was sex-dependently related to UG size during the breeding season, as shown by the significant sex $\times$ UG interaction $(\beta=0.519 \pm 0.243, t=2.128, P=0.039)$; FDB load was not related to UG size in males $(\beta=0.004 \pm 0.209, \quad t=0.024, \quad P=0.981)$, but was significantly positively related in females $(\beta=0.641 \pm 0.215, t=2.982, P=0.007)$. Dur- ing the non-breeding season, FDB load was significantly positively associated with UG size $(\beta=0.615 \pm 0.228, t=2.689, P=0.008)$ in both sexes $($ sex $\times U G$ interaction: $\beta=0.442 \pm 0.480$, $t=0.922, P=0.360)$.

\section{DIscussion}

\section{Feather holes}

Our findings show that the number of feather holes has a negatively relationship to UG size and a positive relationship to FDB abundance in the breeding season. Even though the entire plumage is moulted at the end of breeding, these relationships were also observed for the freshly grown feathers in females in the non-breeding season. Earlier studies have referred to feather holes mostly as feeding traces of feather lice, and thus 
Table 1. Minimum adequate models (MAMs) of generalized linear models of flight feather quality traits of House Sparrows Passer domesticus during the breeding and non-breeding seasons. For the main effect of the fixed factor 'Sex', males are included in the intercept, therefore the reported estimates show the extent to which females differ from males. The sign of estimates indicates the direction of associations.

\begin{tabular}{lrrr}
\hline Response/predictor & Estimate $\pm \mathrm{se}$ & \multicolumn{1}{c}{$t$} & $P$ \\
\hline Breeding & & & \\
Feather holes & & & \\
$\quad$ (Intercept) & $1.380 \pm 0.133$ & 10.370 & $<\mathbf{0 . 0 0 1}$ \\
SMI & $-0.243 \pm 0.112$ & 2.159 & $\mathbf{0 . 0 3 6}$ \\
UG & $-0.365 \pm 0.115$ & 3.175 & $\mathbf{0 . 0 0 2}$ \\
FDB & $0.512 \pm 0.148$ & 3.453 & $\mathbf{0 . 0 0 1}$ \\
Feather wear & & & \\
$\quad$ Intercept) & $3.015 \pm 0.043$ & 68.900 & $<\mathbf{0 . 0 0 1}$ \\
Non-breeding & & & \\
Feather holes & & & \\
$\quad$ (Intercept) & $0.201 \pm 0.238$ & 0.843 & 0.402 \\
Sex (female) & $-1.416 \pm 0.510$ & 2.772 & $\mathbf{0 . 0 0 7}$ \\
UG & $-0.182 \pm 0.291$ & 0.627 & 0.533 \\
FDB & $-0.057 \pm 0.150$ & 0.381 & 0.704 \\
Sex $\times$ UG & $-1.195 \pm 0.523$ & 2.281 & $\mathbf{0 . 0 2 5}$ \\
Sex $\times$ FDB & $0.525 \pm 0.262$ & 2.004 & $\mathbf{0 . 0 4 9}$ \\
Feather wear & & & \\
$\quad$ (Intercept) & $-0.573 \pm 0.361$ & 1.586 & 0.117 \\
Sex (female) & $0.097 \pm 0.347$ & 0.281 & 0.779 \\
UG & $-0.989 \pm 0.329$ & 3.001 & $\mathbf{0 . 0 0 3}$ \\
FDB & $-0.071 \pm 0.253$ & 0.281 & 0.779 \\
Sex $\times$ FDB & $0.733 \pm 0.318$ & 2.301 & $\mathbf{0 . 0 2 4}$ \\
\hline
\end{tabular}

FDB, intensity of infestation by feather-degrading bacteria; SMI, scaled mass index; UG, uropygial gland volume. Significant $P$-values are highlighted in bold.

several studies used the number of holes as a substitute for lice load (Vágási 2014). Additionally, it has been assumed that UG secretions contain insecticides, which hamper the proliferation of lice (Moyer et al. 2003, Møller et al. 2010). Therefore, the negative relationship between the number of feather holes and UG size has been explained based on the basis that preen oil is a defence mechanism against chewing lice (Moreno-Rueda 2010). However, these explanations are not straightforward or well-substantiated in the literature (Vágási 2014).

We report for the first time that FDB load is positively related to feather hole incidence in agreement with an alternative hypothesis for the origin of feather holes (Vágási et al. 2011, Vágási 2014). This is also indicated by the negative relationship between feather hole load and UG size given the protective role of UG secretions against FDB (see below). Because feather lice infestation was not quantified in our study, we cannot exclude the lice origin of the feather holes. However, the lice origin of feather holes seems to be unlikely in this species for the following reasons. Vas et al. (2008) reported that feather holes of small passerines are probably caused by Brueelia spp. lice, but in a previous study we found that House Sparrows from the same population were not infested by Brueelia spp. lice (Pap et al. 2013a). Furthermore, it has been suggested that Ischnoceran lice such as Brueelia spp. are probably incapable of chewing the large barbules and/or barbs of flight feathers (compared with body feathers) due to physical constraints imposed by mandible size (Vágási 2014). The suggestion that FDB are the major causative agents of feather holes, however, requires experimental demonstration and its generality in birds could be studied by means of phylogenetic comparison.

We found a positive association between FDB loads and UG volume in females during breeding and in both sexes in the non-breeding season. This indicates that the preen oil might have an important function in the regulation of plumage-dwelling microbial communities (Shawkey et al. 2003, Soler et al. 2008, Martín-Vivaldi et al. 2010, but see Czirják et al. 2013, Giraudeau et al. 2013). Our findings differ from those of Møller et al. (2009), who recovered a negative relationship between UG size and FDB abundance in breeding Barn Swallows Hirundo rustica. This might stem from the fundamental differences in life-history (e.g. terrestrial vs. aerial foraging) and ecological (e.g. sedentary vs. long-term migrant) attributes of the two species, which might lead to species-specificity in the amount of preen oil produced (Jacob \& Ziswiler 1982, Vincze et al. 2013). However, our results are in line with two experimental studies performed on Great Tits Parus major and Feral Pigeons Columba livia (Jacob et al. 2014b, Leclaire et al. 2015). Both studies found that birds exposed to higher bacterial infection possessed larger UG. Taken together, the UG may partly have evolved, or been seconded, as a defence mechanism against FDB.

The number of feather holes was negatively related to body condition in both sexes during breeding, and only in females during the nonbreeding season. Our results indicate that feather hole emergence can reflect body condition, and that feather quality depends on the individual's general state of health, both of which can be 
influenced by parasites (Saag et al. 2011, Jovani et al. 2014). However, we found no relationship between body condition and FDB load. This suggests that body condition is a determinant of flight feather quality in House Sparrows, which may act independently from FDB or through other parasites (Pap et al. 2013b).

\section{Feather wear}

We found that feather wear was not related to any of the model predictors during the breeding season, when its extent is considerably higher than during the non-breeding season (i.e. after the complete annual moult). Feather wear, however, was negatively related to $U G$ size and positively to FDB abundance in females during the non-breeding season. Our results from the breeding season are in line with previous studies indicating that feather abrasion is the consequence of mechanical friction (Burtt 1986, Francis \& Wood 1989, Jenni \& Winkler 1994), rather than the harmful effect of FDB, as we found no relationship between bacterial load and the intensity of feather wear. However, the lack of relationship between UG and wear is in contrast with a previous study on the same species, in which a negative relationship was reported (Moreno-Rueda 2011). Discrepancies between the two studies might be attributed to the different timing of the studies, pre-breeding by Moreno-Rueda (2011) and breeding in this study. Note that the size of the UG is significantly smaller in both sexes during the pre-breeding period than during breeding, and there is no sex-difference in UG size during pre-breeding, but during breeding females possess significantly larger glands than males (this study, Pap et al. 2010, MorenoRueda 2011). Such seasonal and sex-dependent variations in UG size might influence its relationship with feather abrasion.

The relationships between feather wear and UG size and between feather wear and FDB load, which were apparent in females during the nonbreeding season, indicate a rather slight protective role of preen oil against feather wear and tear. The beneficial effect of preen oil on plumage functionality was demonstrated by the stronger or faster physical feather deterioration in birds that had experimentally blocked or naturally smaller glands (Elder 1954, Jacob \& Ziswiler 1982, Moyer et al. 2003, Giraudeau et al. 2010b, Moreno-Rueda 2011). Still, we found a minor indication that the wear of flight feathers can be mitigated by the preen secretion.

\section{CONCLUSION}

We demonstrate that damage to flight feathers, expressed as abundance of feather holes and extent of feather wear, is associated with diverse intrinsic factors such as body condition, UG size and FDB load, and that these relationships vary seasonally and/or sex-dependently. Our findings indicate that UG might play an important role in the regulation of plumage bacterial abundance, and hence mediate the potentially negative impact of FDB on flight feather quality. Experimental studies are needed to prove causation.

Lőrinc Bărbos, Annamária Fenesi, Attila Marton and Zsófia Mezey are thanked for helping us catch birds. Alina Sesarman, Endre Jakab, Laura Pătraș, Cornelia Ochiș and Bianca Ianc provided logistical help during laboratory work. Csaba Paizs lent us the ultrasonic cleaner. All the laboratory work was carried out at the Molecular Biology Centre, Institute of Interdisciplinary Experimental Research, Babeș-Bolyai University, with the support of Octavian Popescu and Annette Damert. Javier PérezTris, Gregorio Moreno-Rueda, Rauri Bowie and an anonymous reviewer provided constructive criticism. Gareth Dyke kindly helped to polish our English. A.F. was financially supported by an excellence student scholarship of the Babeș-Bolyai University (30068/20/19.01.2012), G.Á.C. by funds from Leibniz Institute for Zoo and Wildlife Research, P.L.P. and C.I.V. by a research grant (PN II. RU TE 291/2010) from the Romanian Ministry of Education. During writing A.F. was financed by an OTKA grant (K112527), P.L.P. by a János Bolyai Research Scholarship of the Hungarian Academy of Sciences and C.I.V. by the Postdoctoral Fellowship Programme of the Hungarian Academy of Sciences. Transport between the Hungarian and Romanian teams was financed by a bilateral TéT grant (RO-HU 679/2013).

\section{REFERENCES}

Barbosa, A., Merino, S., Cuervo, J.J., De Lope, F. \& Møller, A.P. 2003. Feather damage of long tails in Barn Swallows Hirundo rustica. Ardea 91: 85-90.

Bonser, R.H.C. 1995. Melanin and the abrasion resistance of feathers. Condor 97: 590-591.

Burtt, E.H. Jr 1986. An analysis of physical, physiological, and optical aspects of avian coloration with emphasis on 
Wood-Warblers. Ornithological Monographs No. 38. Washington, DC: University of California Press.

Burtt, E.H., Jr \& Ichida, J. 1999. Occurrence of featherdegrading bacilli in the plumage of birds. Auk 116: 364-372.

Burtt, E.H., Jr, Schroeder, M.R., Smith, L.A., Sroka, J.E. \& McGraw, K.J. 2011. Colourful parrot feathers resist bacterial degradation. Biol. Lett. 7: 214-216.

Czirják, G.Á., Møller, A.P., Mousseau, T.A. \& Heeb, P. 2010. Microorganisms associated with feathers of Barn Swallows in radioactively contaminated areas around Chernobyl. Microb. Ecol. 60: 373-380.

Czirják, G.Á., Pap, P.L., Vágási, C.I., Giraudeau, M., Mureșan, C., Mirleau, P. \& Heeb, P. 2013. Preen gland removal increases plumage bacterial load but not that of feather-degrading bacteria. Naturwissenschaften 100: 145151.

Elder, W. 1954. The oil gland of birds. Wilson Bull. 66: 6-31.

Flinks, H. \& Salewski, V. 2012. Quantifying the effect of feather abrasion on wing and tail lengths measurements. J. Ornithol. 153: 1053-1065.

Fox, J. \& Weisberg, S. 2011. An R Companion to Applied Regression, Second Edition. Thousand Oaks, CA: Sage. Available at: http://socserv.socsci.mcmaster.ca/jfox/Books/

6 Companion (accessed XXXXX).

Francis, C.M. \& Wood, D.S. 1989. Effects of age and wear on wing length of Wood-Warblers. J. Field Ornithol. 60: 495503.

Giraudeau, M., Czirják, G.Á., Duval, C., Bretagnolle, V., Gutierrez, C. \& Heeb, P. 2010a. No detected effect of moult on feather bacterial loads in mallards Anas platyrhynchos. J. Avian Biol. 41: 678-680.

Giraudeau, M., Duval, C., Guillon, N., Bretagnolle, V., Gutierrez, C. \& Heeb, P. 2010b. Effects of access to preen gland secretions on mallard plumage. Naturwissenschaften 97: 577-581.

Giraudeau, M., Czirják, G.Á., Duval, C., Bretagnolle, V., Gutierrez, C., Guillon, N. \& Heeb, P. 2013. Effect of preen oil on plumage bacteria: an experimental test with the Mallard. Behav. Processes 92: 1-5.

Gunderson, A.R. 2008. Feather-degrading bacteria: a new frontier in avian and host-parasite research? Auk 125: 972979.

Gunderson, A.R., Forsyth, M.H. \& Swaddle, J.P. 2009. Evidence that plumage bacteria influence feather coloration and body condition of eastern bluebirds Sialia sialis. J. Avian Biol. 40: 440-447.

Ichida, J.M., Krizova, L., LeFevre, C.A., Keener, H.M., Elwell, D.L. \& Burtt, E.H., Jr 2001. Bacterial inoculum enhances keratin degradation and biofilm formation in poultry compost. J. Microbiol. Methods 47: 199-208.

Jacob, J. \& Ziswiler, V. 1982. The uropygial gland. In: Farner, D.S., King, J.R. \& Parkes, K.C. (eds) Avian Biology, Vol. 6: 199-324. New York, NY: Academic Press.

Jacob, J., Eigener, U. \& Hoppe, U. 1997. The structure of preen gland waxes from pelecaniform birds containing 3,7dimethyloctan-1-ol: an active ingredient against dermatophytes. Z. Naturforschung 52: 114-123.

Jacob, S., Colmas, L., Parthuisot, N. \& Heeb, P. 2014a. Do feather-degrading bacteria actually degrade feather colour? No significant effects of plumage microbiome modifications on feather colouration in wild great tits. Naturwissenschaften 101: 929-938.
Jacob, S., Immer, A., Leclaire, S., Parthuisot, N., Ducamp, C., Espinasse, G. \& Heeb, P. 2014b. Uropygial gland size and composition varies according to experimentally modified microbiome in Great Tits. BMC Evol. Biol. 14: 134.

Jenni, L. \& Winkler, R. 1994. Moult and Ageing of European Passerines. New York, NY: Academic Press.

Jovani, R., Montalvo, T. \& Savaté, S. 2014. Fault bars and bacterial infection. J. Ornithol. 155: 819-823.

Leclaire, S., Pierret, P., Chatelain, M. \& Gasparini, J. 2015. Feather bacterial load affects plumage condition, iridescent color, and investment in preening in pigeons. Behav. Ecol. 25: 1192-1198.

Legendre, P. 2014. Imodel2: Model II Regression. R package version 1.7-2. Available at: http://CRAN.R-project.org/ package $=$ Imodel2 (accessed 2 March 2015).

Martín-Vivaldi, M., Peña, A., Peralta-Sánchez, J.M., Sánchez, L., Ananou, S., Ruiz-Rodríguez, M. \& Soler, J.J. 2010. Antimicrobial chemicals in hoopoe preen secretions are produced by symbiotic bacteria. Proc. R. Soc. B 277: 123-130

Merilä, J. \& Hemborg, C. 2000. Fitness and feather wear in the Collared Flycatcher Ficedula albicollis. J. Avian Biol. 31: 504-510.

Møller, A.P. 1991. Parasites, sexual ornaments, and mate choice in the Barn Swallow. In Loye, J.E. \& Zuk, M. (eds) Bird-parasite Interactions: Ecology, Evolution, and Behaviour. 328-343. Oxford: Oxford University Press.

Møller, A.P., Czirják, G.Á. \& Heeb, P. 2009. Feather microorganisms and uropygial antimicrobial defences in a colonial passerine bird. Funct. Ecol. 23: 1097-1102.

Møller, A.P., Erritzøe, J. \& Rózsa, L. 2010. Ectoparasites, uropygial glands and hatching success in birds. Oecologia 163: 303-311.

Moreno-Rueda, G. 2010. Uropygial gland size correlates with feather holes, body condition and wingbar size in the House Sparrow Passer domesticus. J. Avian Biol. 41: 229236.

Moreno-Rueda, G. 2011. House Sparrows Passer domesticus with larger uropygial glands show reduced feather wear. The Ibis 153: 195-198.

Moreno-Rueda, G. 2014. Uropygial gland size, feather holes and moult performance in the House Sparrow Passer domesticus. The Ibis 156: 457-460.

Moyer, B.R., Rock, A.N. \& Clayton, D.H. 2003. Experimental test of the importance of preen oil in rock doves (Columba livia). Auk 120: 490-496.

Nakagawa, S. \& Burke, T. 2008. The mask of seniority? A neglected age indicator in House Sparrows Passer domesticus. J. Avian Biol. 39: 222-225.

Pap, P.L., Vágási, C.I., Osváth, G., Mureșan, C. \& Barta, Z. 2010. Seasonality in the uropygial gland size and feather mite abundance in House Sparrows Passer domesticus: natural covariation and an experiment. J. Avian Biol. 41: 653-661.

Pap, P.L., Adam, C., Vágási, C.I., Benkő, Z. \& Vincze, O. 2013a. Sex ratio and sexual dimorphism of three lice species with contrasting prevalence parasitizing the house sparrow. J. Parasitol. 99: 24-30.

Pap, P.L., Vágási, C.I., Bărbos, L. \& Marton, A. 2013b. Chronic coccidian infestation compromises flight feather quality in House Sparrows Passer domesticus. Biol. J. Linn. Soc. 108: $414-428$. 
Peig, J. \& Green, A.J. 2009. New perspectives for estimating body condition from mass/length data: the scaled mass index as an alternative method. Oikos 118: 1883-1891.

Prater, A.J., Marchant, J.H. \& Vuorinen, J. 1977. Guide to the Identification and Aging of Holarctic Waders (BTO Guide 17). Tring: BTO.

R Core Team. 2014. R: A Language and Environment for Statistical Computing. Version 3.1.1. Vienna: R Foundation for Statistical Computing. Available at: http://www.Rproject.org/ (accessed 10 July 2014).

Ramnani, P., Singh, R. \& Gupta, R. 2005. Keratinolytic potential of Bacillus licheniformis RG1: structural and biochemical mechanism of feather degradation. Can. J. Microbiol. 51: 191-196.

Ruiz-Rodríguez, M., Valdivia, E., Soler, J.J., MartínVivaldi, M., Martín-Platero, A.M. \& Martínez-Bueno, M. 2009. Symbiotic bacteria living in the Hoopoe's uropygial gland prevent feather degradation. J. Exp. Biol. 212: 36213626.

Saag, P., Tilgar, V., Mänd, R., Kilgas, P. \& Mägi, M. 2011. Plumage bacterial assemblages in a breeding wild passerine: relationships with ecological factors and body condition. Microb. Ecol. 61: 740-749.

Saranathan, V. \& Burtt, E.H., Jr 2007. Sunlight on feathers inhibits feather-degrading bacteria. Wilson J. Ornithol. 119: 239-245.

Shawkey, M.D., Pillai, S.R. \& Hill, G.E. 2003. Chemical warfare? Effects of uropygial oil on feather-degrading bacteria. J. Avian Biol. 34: 345-349.

Soler, J.J., Martín-Vivaldi, M., Ruiz-Rodríguez, M., Valdivia, E., Martín-Platero, A.M., Martínez-Bueno, M., PeraltaSánchez, J.M. \& Méndez, M. 2008. Symbiotic association between Hoopoes and antibiotic-producing bacteria that live in their uropygial gland. Funct. Ecol. 22: 864-871.

Swaddle, J. \& Witter, M. 1998. Cluttered habitats reduce wing asymmetry and increase flight performance in European starlings. Behav. Ecol. Sociobiol. 42: 281-287.

Swaddle, J.P., Witter, M.S., Cuthill, I.C., Budden, A. \& McCowen, P. 1996. Plumage condition affects flight performance in Common Starlings: implications for developmental homeostasis, abrasion and moult. J. Avian Biol. 27: 103-111.

Swaddle, J.P., Williams, E.V. \& Rayner, J.M.V. 1999. The effect of simulated flight feather moult on escape take-off performance in starlings. J. Avian Biol. 30: 351-358.

Vágási, C.I. 2014. The origin of feather holes: a word of caution. J. Avian Biol. 45: 431-436.
Vágási, C.I., Pap, P.L., Tökölyi, J., Székely, E. \& Barta, Z. 2011. Correlates of variation in flight feather quality in the great tit Parus major. Ardea 99: 53-60.

Vágási, C.I., Pap, P.L., Vincze, O., Benkö, Z., Marton, A. \& Barta, Z. 2012. Haste makes waste but condition matters: molt rate-feather quality trade-off in a sedentary songbird. PLOS ONE 7: e40651.

Vas, Z., Csörgö, T., Møller, A.P. \& Rózsa, L. 2008. The feather holes on the Barn Swallow Hirundo rustica and other small passerines are probably caused by Brueelia spp. lice. J. Parasitol. 94: 1438-1440.

Vincze, O., Vágási, C.I., Kovács, I., Galván, I. \& Pap, P.L. 2013. Sources of variation in uropygial gland size in European birds. Biol. J. Linn. Soc. 110: 543-563.

Received 18 June 2015; revision accepted 16 December 2015. Associate Editor: Javier Perez-Tris.

\section{SUPPORTING INFORMATION}

Additional Supporting Information may be found in the online version of this article:

Appendix S1. Detailed methodology of the microbiological techniques used to quantify feather-degrading bacterial abundances.

Table S1. The full GLMs demonstrating seasonal (breeding and non-breeding) and sex differences for feather quality traits of House Sparrows Passer domesticus.

Table S2. The full LMs demonstrating seasonal (breeding and non-breeding) and sex differences for scaled mass index, uropygial gland volume and intensity of infestation by feather-degrading bacteria in House Sparrows Passer domesticus.

Table S3. The full GLMs of feather quality traits of House Sparrows Passer domesticus during the breeding and non-breeding seasons.

Table S4. The full LMs on the determinants of feather-degrading bacterial load of House Sparrows Passer domesticus during the breeding and nonbreeding seasons. 


\section{Author Query Form}

Journal: $\quad$ IBI

Article: $\quad 12342$

Dear Author,

During the copy-editing of your paper, the following queries arose. Please respond to these by marking up your proofs with the necessary changes/additions. Please write your answers on the query sheet if there is insufficient space on the page proofs. Please write clearly and follow the conventions shown on the attached corrections sheet. If returning the proof by fax do not write too close to the paper's edge. Please remember that illegible mark-ups may delay publication.

Many thanks for your assistance.

\begin{tabular}{|l|l|l|}
\hline Query reference & Query & Remarks \\
\hline 1 & $\begin{array}{l}\text { AUTHOR: Please confirm that given names (red) and surnames/family } \\
\text { names (green) have been identified correctly. }\end{array}$ & \\
\hline 2 & AUTHOR: Please check that authors and their affiliations are correct. & \\
\hline 3 & $\begin{array}{l}\text { AUTHOR: Moreno Rueda (2010, 2011, 2014) has been changed to } \\
\text { Moreno-Rueda (2010, 2011, 2014) so that this citation matches the } \\
\text { Reference List. Please confirm that this is correct. }\end{array}$ & \\
\hline 4 & AUTHOR: Please check the hierarchy of heading levels. & $\begin{array}{l}\text { AUTHOR: Please give address information for this manufacturer } \\
\text { 'Ecotone': town. }\end{array}$ \\
\hline 5 & $\begin{array}{l}\text { AUTHOR: Please provide the accessed date for reference Fox and } \\
\text { Weisberg (2011). }\end{array}$ & $\begin{array}{l}\text { AUTHOR: Vágási et al. (2012) has not been cited in the text. Please } \\
\text { indicate where it should be cited; or delete from the Reference List. }\end{array}$ \\
\hline 7 &
\end{tabular}

